\title{
Um estudo bibliométrico sobre a evolução da pesquisa da qualidade em serviço
}

\author{
Veridiana Rotondaro Pereira ${ }^{a *}$, Marly Monteiro de Carvalho ${ }^{\mathrm{b}}$, Roberto Gilioli Rotondaro ${ }^{\mathrm{c}}$ \\ a*veridiana_rot@hotmail.com, PRO-POLl-USP, Brasil \\ bmarlymc@usp.br, PRO-POLl-USP, Brasil \\ crotondar@cwaynet.com.br, PRO-POLl-USP, Brasil
}

\begin{abstract}
Resumo
0 objetivo deste trabalho é identificar as obras de maior influência sobre a disciplina de qualidade em serviço, bem como analisar as mudanças ocorridas em sua estrutura intelectual ao longo do tempo. A metodologia adotada baseia-se em técnicas bibliométricas de análise de citação e cocitação aplicadas aos artigos publicados sobre o tema, disponiveis na base de dados ISI Web of Science (1983 a 2011). Para avaliar a produção nacional, uma pesquisa similar foi realizada no Scielo (1993 a 2011), com a adoção de metodologia qualitativa. Os resultados obtidos nas análises de citação e cocitação apontaram o uso de modelos clássicos da qualidade como base para a qualidade em serviço. Em contrapartida, a análise dos dados de ambas as bases indicou uma predominância de adoção pelos pesquisadores de autores e ferramentas das décadas de 1980 e 1990. Destacando-se o setor de saúde em termos de produção.
\end{abstract}

Palavras-chave

Qualidade em serviço. Técnicas bibliométricas. Análise de citação e cocitação. Revisão de literatura.

\section{Introdução}

Desde o início da década de 1980, o campo de gestão de operações tem mostrado particular interesse nas operações de serviços (JOHNSTON, 2005). Inicialmente o foco tratou das possíveis adaptações dos modelos adotados no gerenciamento da manufatura no âmbito de serviços. Muitos trabalhos trataram da aplicação de ferramentas clássicas da qualidade como o TQM em empresas de serviço, avaliando através dos resultados sua aplicabilidade e as customizações necessárias.

Um segundo movimento, iniciado entre as décadas de 1980 e 1990, buscou em inúmeros estudos determinar os componentes da qualidade em serviço, visando assim atender a satisfação do cliente. Cabe ressaltar que olhar a qualidade na perspectiva de serviços é um tema complexo, uma vez que esta depende de fatores relacionados tanto ao prestador quanto ao cliente. Seu construto abstrato é de difícil definição e medição. Na verdade interpretar os sentimentos dos clientes transformando-os em parâmetros concretos é uma tarefa complexa tanto para produtos quanto para serviços.

Muitos trabalhos trataram do tema qualidade em serviço, como o modelo conceitual de qualidade em serviço de Parasuraman, Zeithaml e Berry (1985) e seu instrumento de medida da qualidade em serviço, SERVQUAL (PARASURAMAN; ZEITHAML; BERRY, 1988; ZEITHAML; PARASURAMAN; BERRY, 1990). Cita-se também o SERVPERF, proposto por Cronin e Taylor (1992), instrumento baseado no SERVQUAL porém considerando apenas as percepções dos clientes. Outra ferramenta muito utilizada na área é a técnica do incidente crítico (TIC), desenvolvida por Flanagan (1954), que ao contrário dos modelos SERVQUAL e SERVPERF, contrói o instrumento de pesquisa baseado em informações coletadas diretamente com o cliente. No entanto, apesar de terem servido como base para muitas pesquisas no campo da gestão de serviços, essas ferramentas foram também alvo de muitas críticas (JOHNSTON, 1995). 
Recentemente um novo movimento no campo da gestão de operações em serviço tem sido de grande interesse para os pesquisadores. Trata-se do papel dos serviços em empresas tradicionalmente de manufatura, num processo denominado servitização (BAINES et al., 2007).

Como apontado por Croom (2009), uma parte fundamental de qualquer pesquisa acadêmica é revisar a literatura acadêmica existente no campo de interesse. Assim, uma vez que a disciplina de qualidade em serviço atingiu certo grau de maturidade, torna-se possivel e também interessante realizar um levantamento da literatura gerada pela comunidade científica sobre esse tema. Desse modo, este trabalho busca uma visão sobre a pesquisa na área de qualidade em serviço e sua evolução ao longo do tempo considerando as obras de um grande número de pesquisadores nesse campo durante um determinado período, utilizando técnicas bibliométricas. Como sugerido por White e MacCain (1998), o objetivo é verificar a forma como a disciplina evoluiu, concentrando e descrevendo o que já foi publicado.

Este artigo está estruturado em 5 seções. $\mathrm{Na}$ síntese do quadro teórico, apresentada na seção 2, são explorados os principais aspectos relacionados à gestão de serviços e sua evolução. A seção 3 mostra os aspectos metodológicos aplicados na pesquisa, cuja abordagem híbrida envolve tanto bibliometria quanto análise de conteúdo. A seção 4 apresenta e discute os resultados da pesquisa. Finalmente a seção 5 traz as conclusões.

\section{Serviços: conceitos, características e qualidade em serviços}

Por se tratar de um tema bastante discutido tanto no âmbito acadêmico quanto no empresarial, existem diversas definições para o termo serviço. Para a NBR ISO 9004-3 serviço compreende tanto as atividades entre fornecedor e cliente quanto as atividades internas do fornecedor, visando atender às necessidades do cliente.

Heskett (1986, p. 2) define o conceito de serviço como o modo pelo qual “[...] a organização gostaria de ter seus serviços percebidos por seus clientes, funcionários, acionistas e financiadores."

A definição da NBR é mais próxima da materialidade, enquanto a proposta de Heskett (1986) trata da perspectiva organizacional e, neste caso, o conceito de serviço é visto como uma proposição de negócio.

Edvardsson and Olsson (1996) referem-se ao conceito de serviço como o protótipo para o serviço e o define como a descrição detalhada do que será feito para o cliente (quais necessidades e desejos serão satisfeitos) e como isso será alcançado. Essa abordagem do que e como também é utilizado por Lovelock, Vandermerwe e Lewis (1999), que separam o "conceito de marketing de serviços", como os benefícios para o cliente (ou seja, ao o que) e o "conceito de operações de serviços" como a especificação de como o serviço será entregue.

Edvardsson et al. (2000) definem o conceito de serviço como uma descrição detalhada das necessidades dos cliente a serem satisfeitas, como devem ser satisfeitas, o que deve ser feito para o cliente, e como isso será alcançado. Clark, Johnston Shulver (2000) e Johnston e Clark (2001) definem mais detalhadamente o conceito de serviço:

- Operação de serviço: a forma como o serviço é prestado;

- Experiência de serviço: a experiência direta do cliente com o serviço;

- Resultado do serviço: os benefícios e resultados do serviço para o cliente; e

- Valor do serviço: os benefícios que o cliente percebe em relação ao serviço versus custo do serviço.

Segundo Goldstein et al. (2002), essa divisão entre $o$ que e como permite identificar os vários elementos do conceito de serviços, compará-los com as necessidades dos clientes e então projetar e fornecer esses elementos. No entanto, essa abordagem "em pedaços" muitas vezes mascara a complexidade de muitos serviços e também ignora o fato que o serviço pode ser visto por seus clientes como uma "experiência completa".

Mais recentemente Lovelock (2000) definiu serviço como um ato ou desempenho oferecido por uma parte à outra. Sendo esse desempenho essencialmente intangivel mesmo quando o processo está vinculado a um produto físico. A relação com o produto reflete um movimento feito pelas empresas em resposta às mudanças nas dinâmicas de competitividade, onde as companhias passaram a agregar produtos a seus serviços ou serviços a seus produtos de forma a oferecer um pacote de valor para seus clientes. Esse pacote de valor ou solução pode constituir-se tanto de componentes normalmente considerados como serviços quanto componentes normalmente considerados como bens físicos, sendo esse conjunto composto por instalações de apoio, bens facilitadores, serviços explícitos e implícitos (CORRÊA; CAON, 2002; FITZSIMMONS; FITZSIMMONS, 2005).

Considerando esses dois componentes, é importante ressaltar, como apontado por alguns autores (LOVELOCK; GUMMESSON, 2004; ROTONDARO; CARVALHO, 2006; VARGO; LUSCH, 2004), que nem sempre é possível identificar a diferença entre produtos 
e serviços, uma vez que é difícil apresentar um exemplo claro de um serviço ou de um bem físico. Para Corrêa e Caon (2002) existem três principais diferenças entre produtos e serviços: simultaneidade de produção e consumo ou estocabilidade, intensidade e participação do cliente no processo produtivo e intangibilidade.

Quanto à estocabilidade, normalmente considera-se que produtos físicos podem ser estocados e serviços não. No entanto, mesmo os fabricantes de bens devem levar em consideração outros fatores como as demandas de mercado, durabilidade de seus produtos e custos de estocagem. Para os serviços o prazo de validade é zero; isso se deve ao fato de que o serviço deve ser produzido e consumido simultaneamente. Assim, como apontado por Corrêa e Caon (2002), do ponto de vista da gestão de operações o foco deve ser o grau de estocabilidade do produto (ou produtos), pois em alguns casos as questões relativas à estocabilidade de alguns produtos podem ser tão complexas quanto às enfrentadas em serviços. Um exemplo seria a produção e consumo de um café expresso em uma padaria. Mesmo que o dono do estabelecimento saiba que a demanda é maior pelas manhãs e hora do almoço, ele não nivela sua produção, pois a durabilidade do café impossibilita tal ação.

A segunda diferença trata da intensidade e participação do cliente no processo produtivo. Inicialmente a presença do cliente era colocada como fundamental em operações de serviço, no entanto, com o aumento dos serviços prestados de forma remota, como a internet, essa condição vem se alterando, assim o cliente não precisa necessariamente estabelecer um contato com o fornecedor, mas sim com algum aspecto do processo produtivo. Quanto à parcela referente ao produto, nas últimas décadas, empresas tradicionalmente de manufatura têm agregado serviços a seus produtos, em um fenômeno denominado servitização. Nesse processo muitas vezes o fabricante permanece com a propriedade do bem e o cliente passa, em alguns casos, a participar do processo produtivo (BAINES et al., 2007). A terceira diferença refere-se a questões relativas à intangibilidade que está relacionada ao modo de avaliação da qualidade do pacote de valor oferecido ao cliente. Devido a sua intangibilidade o serviço é difícil de ser avaliado, pois o cliente usará de sua percepção nesse processo, porém, conforme apontado por Corrêa e Caon (2002), o foco não deve ser a intangibilidade ou tangibilidade, mas sim suas implicações na avaliação da qualidade.

No entanto, para alguns autores (LOVELOCK; GUMMESSON, 2004; VARGO; LUSCH, 2004) as características tradicionalmente associadas ao conceito de serviço (intangibilidade, heterogeneidade, inseparabilidade e perecibilidade) não distinguem realmente produtos de serviços. Lovelock e Gummesson
(2004) sugerem que a experiência do cliente em um processo de serviço, ou uma saída de serviço, pode ser bastante tangível, enquanto que muitos serviços estão cada vez mais homogêneos devido à padronização e automação. No que se refere à inseparabilidade, em alguns casos como a serviços de limpeza ou de seguro, o cliente não precisa estar diretamente envolvido, e a terceirização de serviços chega mesmo a aumentar a separabilidade (ARAUJO; SPRING, 2006).

Assim, por ser utilizado em uma gama heterogênea de atividades, segundo Johnstone, Dainty e Wilkinson (2009), torna-se complexa uma definição serviço amplamente aplicável para o termo serviço.

0 tema qualidade em serviço é complexo, pois depende de fatores relacionados tanto ao prestador quanto ao cliente. Seu construto abstrato é de difícil definição e medição. Na verdade interpretar os sentimentos dos clientes transformando-os em parâmetros concretos é uma tarefa complexa tanto para produtos quanto para serviços. Com a finalidade de auxiliar o processo de identificação e interpretação do comportamento e intenções dos clientes com relação a um produto, foram propostas algumas metodologias como o design Kansei (SCHÜTTE, 2004), um método para traduzir os sentimentos e as sensações em características de um produto. Originalmente o design Kansei focava apenas em produtos, porém recentemente estudos têm tratado da área de serviços ampliando e melhorando a aplicabilidade dessa ferramenta (NISHINO et al., 1999).

Alguns autores (ZEITHAML; BERRY; PARASURAMAN, 1988; HESKETT; SASSER; HART, 1994; FITZSIMMONS; FITZSIMMONS, 2005) acreditam que o conceito de qualidade em serviço baseia-se na diferença entre a expectativa de um cliente com o serviço a ser prestado e sua percepção de como ele é prestado. No entanto, esse conceito é criticado por Cronin e Taylor (1992) e Carman (1990), que acreditam na adoção de um sistema de avaliação de desempenho da qualidade em serviço baseado somente na percepção dos clientes.

Apesar de muitas vezes serem consideradas da mesma forma, parece haver um consenso (BITNER, 1990; BOLTON; DREW, 1991; CRONIN; TAYLOR, 1992; ZEITHAML; BITNER, 2003) de que satisfação e qualidade são fundamentalmente diferentes quanto às suas causas básicas e àquilo que produzem como resultado. Enquanto a satisfação refere-se ao resultado de transações individuais de serviços e de todo o encontro de serviço, a qualidade em serviço trata da impressão geral do cliente sobre a relativa superioridade/inferioridade de uma organização e seus serviços (BITNER; HUBBERT, 1995). A qualidade em serviço concentra-se especificamente nas dimensões do serviço e, como mostra a Figura 1, ela possui dimensões 
específicas que dependem da percepção do cliente, já a satisfação é influenciada não só pelas percepções acerca da qualidade dos serviços, mas também por fatores como a qualidade do produto, preço e pelas percepções a respeito de fatores situacionais e pessoais.

Outro fator importante a ser considerado refere-se ao desempenho do funcionário. Para alguns autores (BITNER, 1992; HARTLINE; MAXHAM; MCKEE, 2000; HESKETT, 1990; SLÅTTEN, 2008; SLATTEN; SVENSSON; SVAERI, 2011) a satisfação também depende de fatores relacionados à percepção do cliente quanto à qualidade do desempenho dos funcionários de serviço (Figura 1).

A qualidade em serviços é um ator predominante nas avaliações dos clientes em serviços puros e fundamental em serviços agregado a produto. Segundo Johnston (1995) é fundamental identificar os fatores determinantes da qualidade em serviço e assim poder medir, controlar e melhorar a qualidade dos serviços percebida pelo cliente, durante o processo de serviço. Na verdade essa área de pesquisa é bastante explorada na literatura. Muitos trabalhos tratam da identificação e classificação dos determinantes da qualidade em serviço, no entanto o recorte e o método de pesquisa adotado podem atuar como limitadores na generalização e consenso sobre os determinantes ou grupo de determinantes a serem considerados (GOLDSTEIN et al., 2002; JOHNSTON, 1995).

Nas décadas de 1980 e 1990 muitos trabalhos trataram do tema qualidade em serviço. Parasuraman, Zeithaml e Berry (1985) propuseram um modelo conceitual de qualidade em serviço que incluía uma lista de dez determinantes ou dimensões da qualidade em serviço. Em um passo seguinte de seus estudos, Berry, Zeithaml e Parasuraman (1985) reduziram para cinco o número de dimensões que compunham a qualidade em serviço: tangíveis, confiabilidade, agilidade, garantia e empatia, as quais foram utilizadas como base para seu instrumento de medida da qualidade em serviço, SERVQUAL (PARASURAMAN, ZEITHAML; BERRY, 1988; ZEITHAML, PARASURAMAN; BERRY, 1990). Segundo eles, independente do serviço em estudo, a confiabilidade era a dimensão mais importante, seguida por agilidade, garantia e empatia.

Apesar de terem servido como base para muitas pesquisas no campo da gestão de serviços, a ferramenta SERVQUAL e suas cinco dimensões foram alvo de muitas críticas (JOHNSTON, 1995). A proposição de Berry, Zeithaml e Parasuraman (1985) de que essa ferramenta poderia ser utilizada para avaliar a qualidade em uma ampla gama de empresas de serviços foi constestada em vários estudos (JOHNSTON, 1995), citam-se Finn e Lamb (1991) em suas pesquisas no varejo e Cronin e Taylor (1992) em seus estudos em bancos, empresas de controle de pestes, limpeza a seco e fast foods.

Cronin e Taylor (1992) propuseram ainda o SERVPERF, instrumento baseado no SERVQUAL, porém considerando apenas as percepções dos clientes, que segundo eles seria mais eficiente.

Outra ferramenta muito utilizada na identificação dos determinantes da qualidade em serviço é a técnica do incidente crítico ( $\mathrm{TlC}$ ), desenvolvida por Flanagan (1954). Ao contrário dos modelos SERVQUAL e SERVPERF que se baseiam em um questionário predefinido, essa técnica contrói o instrumento de pesquisa baseado em informações coletadas diretamente com o cliente, sendo este qualquer pessoa que receba um serviço ou produto, dentro ou fora de uma organização. 0 método gera uma lista de comportamentos bons e ruins que pode ser usada em avaliações de desempenho além

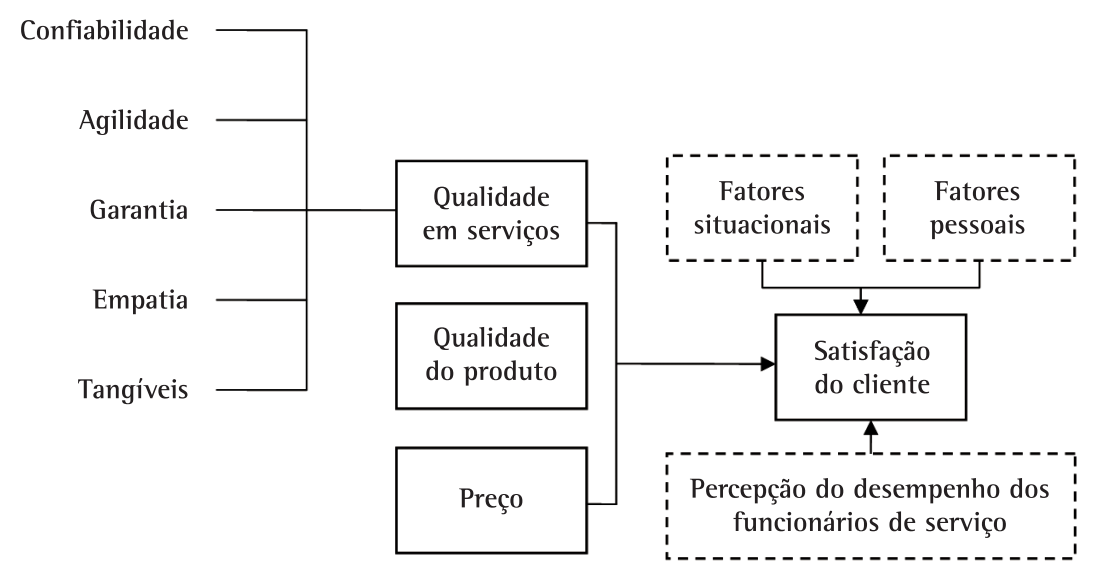

Figura 1. Percepções de clientes sobre qualidade e satisfação do cliente. Fonte: adaptado de Zeithaml e Bitner (2003), Slatten (2008) e Hartline, Maxham e Mckee (2000). 
de identificar possíveis fontes de problemas em um produto ou serviço. Algumas de suas vantagens são sua flexibilidade de uso, foco em pontos importantes e a possibilidade de ser aplicado através de questionários ou entrevistas. O TIC também é muito adotado em estudos sobre a recuperação de serviços. No entanto, essa técnica apresenta algumas desvantagens. Uma delas seria o fato de que os incidentes podem ter ocorrido algum tempo antes da coleta dos dados, e então a percepção dos respondentes pode ter sido alterada ou reinterpretada em virtude de algum evento posterior. Como a técnica exige dos entrevistados algum tempo e esforço para descrever situações em palavras, pode-se esperar uma baixa taxa de resposta (JOHNSTON, 1995). No uso do TIC em estudos de recuperação de serviço, enquanto essa técnica permite que os entrevistados relatem suas próprias experiências com o serviço, a análise trata apenas do contato de recuperação do serviço e não do serviço como um todo (GOLDSTEIN et al., 2002). Uma desvantagem adicional, em ambos os casos, refere-se à dificuldade de processamento e análise do material coletado.

Atualmente, grande parte dos empregos nas economias industrializadas encontra-se no setor de serviços, que concentra cerca de $70 \%$ das vagas disponíveis (MAGL10 et al., 2009; NEELY, 2007). No entanto, o crescimento dos serviços não se limita apenas ao desempenho do próprio setor. Nas últimas décadas, observa-se que empresas tradicionalmente de manufatura têm agregado serviços a seus produtos, como forma de sobreviver às novas tendências das economias desenvolvidas (BAINES et al., 2007; OLIVA; KALLENBERG, 2003). Com isso, alguns autores (LUSCH; VARGO; O'BRIEN, 2007; VARGO; LUSCH, 2004) argumentam que como consequência todas as economias são economias de serviço.

Assim, é preciso olhar além da satisfação do cliente, pensando na inovação das novas soluções de serviço a serem oferecidas. Nesse sentido Andreassen e Streukens (2009) elaboraram um estudo com o objetivo de abordar "o que os clientes realmente precisam”, através da investigação do conteúdo de diálogos em fóruns de discussão na internet. Como resultado, os autores constaram alguns pontos importantes. Verificou-se que ao "ouvir" os desejos dos clientes, as empresas podem obter uma opinião (feedback) mais rápida de seus clientes. Quando as necessidades do cliente se refletem em um serviço futuro, tem-se melhor qualidade de informação de mercado levando a tomadas de decisão mais acertadas. Por fim, as ações baseadas em respostas dos clientes tornam-se mais eficazes e devem estar refletidas nos serviços existentes e nas práticas de negócio.

\section{Metodologia}

Para atingir o objetivo desse trabalho de obter uma visão sobre a pesquisa na área de qualidade em serviço e sua evolução ao longo do tempo, considerando as obras de um grande número de pesquisadores nesse campo, optou-se por uma abordagem híbrida com análise de conteúdo e bibliometria, considerando-se a hipótese de que as referências bibliográficas citadas nos trabalhos de investigação são uma indicação confiável de sua influência (CULNAN, 1987; TAHAl; MEYER, 1999). Como apontado por Karlsson (2009), a combinação de metodologias em pesquisas na área de administração de operações (operations management) contribui para enriquecer o estudo.

0 termo bibliometria refere-se às análises matemáticas e estatísticas dos padrões que aparecem nas publicações e uso de documentos (DIODATO, 1994). Este estudo utiliza as técnicas conhecidas como análise de citação e cocitação. A análise da citação é baseada na premissa de que autores citam documentos por eles considerados importantes no desenvolvimento de suas pesquisas. Por isso, trabalhos frequentemente citados são prováveis de terem exercido maior influência sobre a disciplina do que aqueles menos citados (CULNAN, 1987; TAHAl; MEYER, 1999). Da mesma maneira, a análise de cocitação de documentos registra o número de artigos que citam pares de documentos iguais e é interpretada como medida de similaridade do conteúdo desses dois documentos.

Optou-se por adotar artigos publicados em journals como base para esta pesquisa, devido a seu alto grau de confiabilidade, considerando que estes são submetidos a uma revisão crítica por parte de seus avaliadores, geralmente pesquisadores de renome na disciplina em questão. Artigos são conhecidos como "conhecimento certificado" (certified knowledge), e o uso de citações de artigos é uma prática padrão que assegura a confiabilidade dos resultados (RODRIGUEZ; NAVARRO, 2004). Cabe ressaltar, no entanto, que o estudo bibliométrico não deve ser considerado substituto de uma análise profunda dos textos, utilizando análises de conteúdo e técnicas de classificação e codificação (WHITE; MACCAIN, 1998; RODRIGUEZ; NAVARRO, 2004).

A amostra inicial foi elaborada através de informações extraídas da base ISI Web of Science. Optou-se por esse banco de dados, pois seu processo de busca acessa artigos que estão disponíveis em outras bases, como o Scopus, ProQuest e Wiley, e que são publicados em periódicos indexados e classificados com fator de impacto no Jornal Citation Reports (JCR). Além disso, ao contrário de outros bancos de dados, o ISI Web of Science permite a criação de um 
conjunto de metadados que pode ser importado, o que é essencial para a análise bibliométrica. Os dados coletados sobre os trabalhos incluem resumos, referências citadas, número de vezes citado, autores, instituições, países e o fator de impacto da revista.

A busca dos artigos foi realizada selecionando-se todas as publicações que possuíam a frase quality management e a palavra service mencionadas no item assunto, gerando um total de 1.007 "artigos". Esse resultado foi refinado considerando como tipo de documento apenas artigos (634). Das 100 primeiras categorias da ISI Web of Science, optou-se por aquelas mais alinhadas à área de pesquisa em gestão de operações e com maior número de publicações. Assim, realizou-se um novo filtro considerando duas áreas temáticas (subject area), management (201) e operations research \& management science (55) em 47 journals. Vale destacar que os periódicos em geral são classificados em mais de uma área temática, como por exemplo o IEEE (transactions on engineering management), classificado tanto na área de engenharia (engineering) quanto na área de administração (management).

Antes de exportar os dados da base ISI Web of Science, realizou-se uma análise dos artigos selecionados excluindo-se aqueles que apenas mencionavam o termo serviço, mas que não se referiam propriamente à análise da qualidade nesse setor, resultando um total de 226 artigos selecionados para geração do arquivo. 0 artigo mais antigo incluído na base foi publicado em 1983 e o mais recente em 2011.

0 arquivo texto gerado foi importado no software Sitikis (SCHILDT, 2002) para elaboração das análises bibliométricas baseadas em análises de citação e cocitação. Primeiro realizou-se a análise das referências usadas em todos os artigos pesquisados, de modo a identificar os trabalhos que apresentaram maior impacto na comunidade científica. As análises de cocitações foram baseadas nos documentos mais citados no período selecionado para estudo, e a análise de cocitação baseou-se nas frequências de distribuição obtidas da contagem de citações, formando todos os pares possiveis de documentos mais frequentemente citados, considerando todos os artigos que citaram ambos os documentos (Figura 2).

Dos trabalhos selecionados, dois não foram importados pelo sistema, pois não possuíam resumo e por isso não puderam ser considerados nos estudos.

Com a finalidade de avaliar a produção nacional sobre o tema, realizou-se a mesma busca na base de dados Scielo. Os parâmetros da pesquisa selecionados foram "artigos", "indice de assuntos", termo de busca "servi"." 0 asterisco permite pegar todas as grafias de serviço possíveis para o inglês e português, a base inclusive não trabalha com a cedilha que aparece no português serviço, por exemplo.

A primeira busca resultou em 96 termos que continham a palavra serviço (em quatro idiomas, inglês, português, espanhol e francês), totalizando 1.044 artigos. Depois se passou a triar os termos relacionados aos serviços com tópicos de qualidade, resultando a seguinte variedade de termos na revista Produção, por exemplo: service process improvement or service quality or service recovery or services quality or servperf or servqual or servqual scale.

A pesquisa selecionando por termos relacionados à qualidade e a serviços resultou em um total de 37 artigos para publicações no "Brasil". Deu-se especial atenção às três revistas nacionais pertencentes ao Scielo, com maior classificação no Qualis das Engenharias 111: Produção, Gestão \& Produção e Pesquisa Operacional.

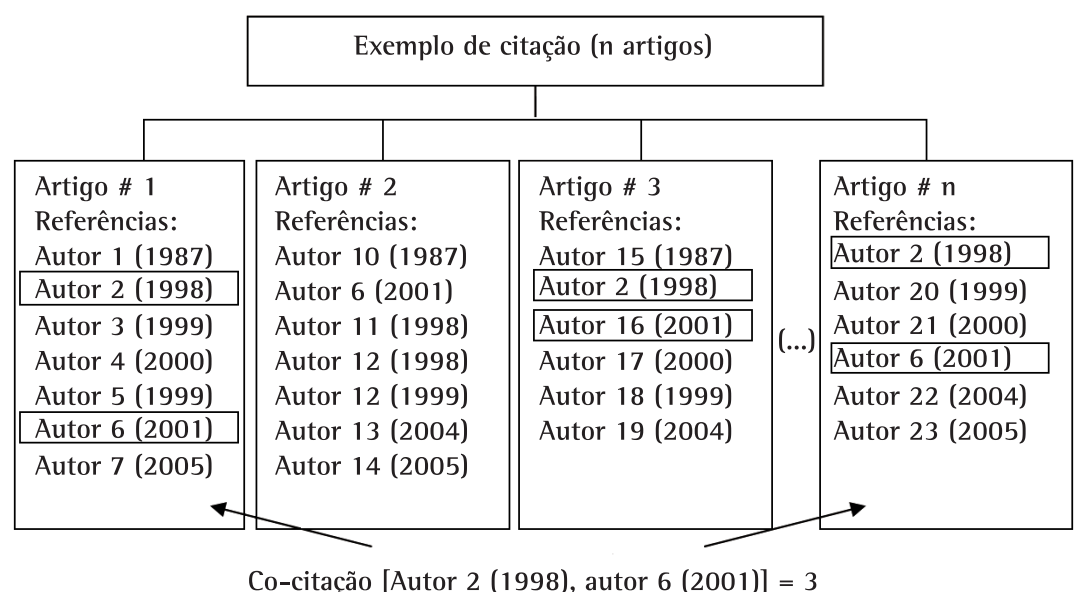

Figura 2. Esquema de contagem de cocitação. Fonte: adaptado de Rodriguez e Navarro (2004). 


\section{Pesquisa sobre qualidade em serviço: análise dos dados}

Nesta seção serão analisados e discutidos os dados obtidos nas pesquisas realizadas na base de dados ISI Web of Science para a produção internacional e no Scielo para a produção nacional sobre o tema qualidade em serviço.

\subsection{Dados obtidos através da base $I S I$ Web of Science}

Os dez autores mais citados estão apresentados com suas respectivas áreas de atuação no Quadro 1. Esse ranking divide-se em dois grupos distintos em termos de área de atuação, marketing e qualidade em serviço, e o segundo, gerenciamento da qualidade e gestão da qualidade total (total quality management - TQM). lsoladamente, tem-se em segundo lugar na lista dos mais citados, Schneider, que, apesar de ser da área de psicologia, trata em uma de suas linhas de pesquisa sobre modelos organizacionais para a qualidade em serviço, estudando a relação entre as experiências de trabalho do empregado e a percepção da qualidade do serviço dos clientes por ele atendidos (SCHNEIDER; PAUL; WHITE, 1998).

Os journals mais presentes nas citações foram Total Quality Management (32 citações), Total Quality Management \& Business Excellence (22 citações), Service Industries Journal (10 citações) e International Journal of Service Industry Management (8 citações). Seguindo a mesma linha dos autores, os journals mais presentes nas citações dividem-se em duas áreas, gerenciamento da qualidade e qualidade em serviço.

Através dos dados é possível verificar a evolução da pesquisa na área de qualidade em serviço pelo número de publicações por ano sobre esse tema, como mostra a Figura 3. Esses dados devem ser interpretados levando-se em consideração dois pontos importantes: primeiro, que a base de dados Web of Science possui, em sua maioria, informações referentes a publicações mais recentes e, segundo, que existe uma tendência crescente na comunidade acadêmica em publicar. De acordo com o número de publicações, destacam-se picos em 2001, 2003 e mais recentemente em 2010; no entanto, em geral o tema qualidade em serviço tem sido abordado de forma regular. Em relação a valores gerais, nota-se que o volume de publicações não apresenta valores significativos quando comparados com outras linhas de pesquisa como a área de medida de desempenho, que obteve mais de 100 publicações em 2003 (NEELY, 2005).

Aprofundando-se as análises, é possível verificar a frequência de citações por artigo, conforme Quadro 2.
Aqui novamente aparece a divisão em duas áreas de interesse, qualidade em serviço (artigos 1, 2 e 9) e gerenciamento da qualidade (artigos 4, 5, 6, 7 e 8).

Fazendo-se um comparativo entre autores e trabalhos mais citados (Quadros 1 e 2 respectivamente), há o cruzamento de um autor da área de qualidade em serviço, Parasuraman, e um da área de gerenciamento da qualidade, Flynn. Destaca-se que os trabalhos mais citados foram publicados em sua maioria nas décadas de 1980 e 1990.

Outro ponto a ser notado sobre os dados da Figura 4 é que a frequência de citação é relativamente similar para os demais trabalhos, indicando que ao longo dos anos os pesquisadores da área de qualidade em serviço têm usado as mesmas referências como embasamento para seus trabalhos.

Através do software UCINET(BORGATTI; EVERETT; FREEMAN, 1999), elaborou-se uma análise da rede de citações mais comuns entre os artigos pesquisados. A Figura 5 mostra o padrão de citação para os trabalhos mais influentes (aqueles com citação acima de cinco enquanto os artigos citados deveriam ser citados pelo menos três vezes), sendo que a espessura da linha indica a frequência com que os dois artigos conectados foram cocitados.

A rede formada pela análise de citação/cocitação apresenta três pontos importantes: distinção entre linhas de pesquisa, instrumentos de pesquisa usados

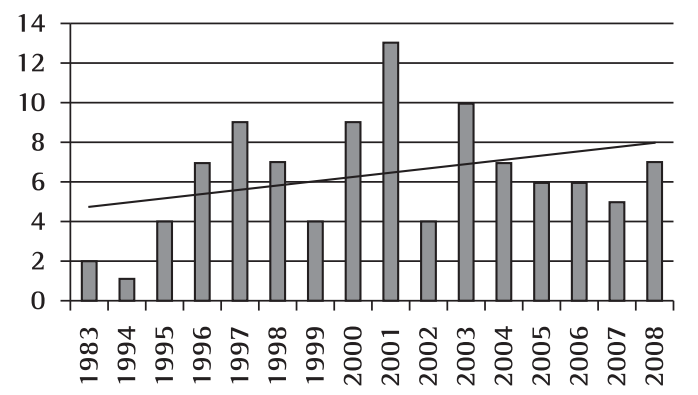

Figura 3. Número de publicações por ano na área de gerenciamento da qualidade em serviços.

Quadro 1. Lista dos dez autores com maior número de citações.

\begin{tabular}{ccc}
\hline Autor & Área de atuação & $\begin{array}{c}\text { N. }{ }^{\circ} \text { de } \\
\text { citações }\end{array}$ \\
\hline Parasuraman, A. & Marketing e qualidade em serviço & 79 \\
Schneider, B. & Psicologia - qualidade em serviço & 31 \\
Bitner, M. J. & Marketing e qualidade em serviço & 29 \\
Gronroos, C. & Marketing e gerenciamento de serviço & 29 \\
Flynn, B. B. & Gerenciamento da qualidade, TQM & 29 \\
Zeithaml, V. A. & Marketing e qualidade em serviço & 28 \\
Berry, L. L. & Marketing e qualidade em serviço & 28 \\
Kanji, G. K. & Gerenciamento da qualidade, TQM & 28 \\
Wilkinson, A. & Gerenciamento da qualidade, TQM & 22 \\
Juran, J. M. & Gerenciamento da qualidade, TQM & 20 \\
\hline
\end{tabular}


Quadro 2. Trabalhos de gerenciamento da qualidade em serviços mais citados.

\begin{tabular}{|c|c|c|c|}
\hline Autor & Artigo & Ano & Citações \\
\hline $\begin{array}{l}\text { Parasuraman, A.; Zeithaml, } \\
\quad \text { V. A. e Berry, L. L. }\end{array}$ & $\begin{array}{l}\text { SERVQUAL - a multiple-item scale for measuring consumer perceptions of service } \\
\text { quality. Journal of Retailing, Volume: } 64 \text {, lssue: } 1, \text { p. 12-40. }\end{array}$ & 1988 & 22 \\
\hline $\begin{array}{l}\text { Parasuraman, A.; Zeithaml, } \\
\quad \text { V. A. e Berry, L. L. }\end{array}$ & $\begin{array}{l}\text { A conceptual-model of service quality and its implications for future research. } \\
\text { Journal of Marketing, Volume: } 49 \text {, lssue: } 4 \text {, p. } 41-50 \text {. }\end{array}$ & 1985 & 19 \\
\hline $\begin{array}{l}\text { Saraph, J. V.; Benson, P. G. e } \\
\text { Schroeder, R. G. }\end{array}$ & $\begin{array}{l}\text { An instrument for measuring the critical factors of quality management. Decision } \\
\text { Sciences, Volume: } 20 \text {, lssue: } 4 \text {, p. } 810-829\end{array}$ & 1989 & 18 \\
\hline Powell, T. C. & $\begin{array}{l}\text { Total quality management as competitive advantage - a review and empirical-study. } \\
\text { Strategic Management Journal, Volume: } 16 \text {, lssue: } 1 \text {, p. } 15-37 \text {. }\end{array}$ & 1995 & 16 \\
\hline $\begin{array}{l}\text { Flynn, B. B.; Schroeder, R. G. } \\
\text { e Sakakibara, S. }\end{array}$ & $\begin{array}{l}\text { A framework for quality management research and an associated measurement } \\
\text { instrument. Journal of Operations Management, Vol.11, p. 339-66 }\end{array}$ & 1994 & 13 \\
\hline $\begin{array}{l}\text { Dow, D.; Samson, D. e } \\
\text { Ford, S. }\end{array}$ & $\begin{array}{l}\text { Exploding the myth: do all quality management practices contribute to superior } \\
\text { quality performance? Production and Operations Management, Volume: } 8 \text {, lssue: } 1 \text {, } \\
\text { p. } 1-27 \text {. }\end{array}$ & 1999 & 13 \\
\hline $\begin{array}{l}\text { Ahire, S. L.; Golhar, D. Y. e } \\
\text { Waller, M. A. }\end{array}$ & $\begin{array}{l}\text { Development and validation of TQM implementation constructs. Decision Sciences, } \\
\text { Volume: } 27 \text {, lssue: } 1 \text {, p. } 23-56 .\end{array}$ & 1996 & 12 \\
\hline Black, S. A. e Porter, L. J. & $\begin{array}{l}\text { Identification of the critical factors of TQM. Decision Sciences, Volume: } 27 \text {, } \\
\text { lssue: } 1, \text { p. 1-21. }\end{array}$ & 1996 & 11 \\
\hline Cronin, J. J. e Taylor, A. S. & $\begin{array}{l}\text { Measuring service quality - a reexamination and extension. Journal of Marketing, } \\
\text { Volume: } 56 \text {, lssue: } 3 \text {, p. 55-68. }\end{array}$ & 1992 & 11 \\
\hline Bitner, M. J. & $\begin{array}{l}\text { Evaluating Service Encounters: the effects of physical surroundings and employee } \\
\text { responses. Journal of Marketing, v. 54, p. } 69-82 \text {. }\end{array}$ & 1990 & 10 \\
\hline
\end{tabular}

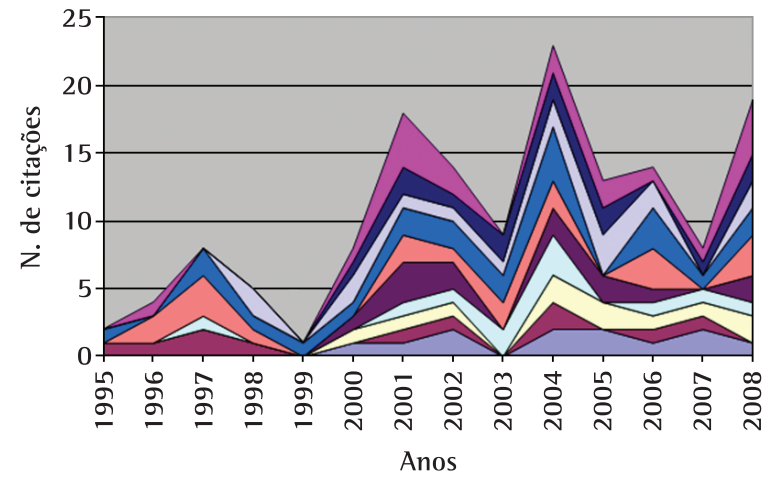

- Saraph et al. (1989)

- Samson et al. (1999)

- Powell (1995)

- Parasuraman et al. (1988)

- Parasuraman et al. (1985)

- Flynn et al. (1994)

- Cronin e Taylor (1992)

- Black e Porter (1996)

- Bitner (1990)

- Ahire et al. (1996)

Figura 4. Mudanças no padrão de frequência de citação.

na área de qualidade em serviço e utilização das metodologias clássicas da qualidade para a área de serviços.

Quanto às linhas de pesquisa, verificam-se três principais grupos de pesquisa. 0 grupo central refere-se a gerenciamento da qualidade e TQM - Dow, Samson e Ford (1999), Saraph, Benson e Schroeder (1989), Black e Porter (1996), Crosby (1979), Powell (1995), Ahire, Golhar e Waller (1996), Flynn, Schroeder e Sakakibara (1994, 1995) e Deming (1986). O segundo grupo com um número menor de representantes refere-se à área de qualidade em serviço - Parasuraman, Zeithaml e Berry $(1985,1988)$ e Cronin e Taylor (1992). Por fim, na parte inferior da rede aparece o autor Nunnally (1978) com seu trabalho sobre a teoria da psicometria, usada como referência na avaliação das escalas usadas nos instrumentos de medição através do valor do alpha de Cronbach. Novamente nota-se que os autores e seus respectivos trabalhos remetem às décadas de 1980 e 1990 e o trabalho de Nunnally de 1978.

A parte mais densa da rede no centro à esquerda da Figura 5 sugere uma grande referência aos trabalhos de Parasuraman, Zeithaml e Berry (1988) e Cronin e Taylor (1992) e suas ferramentas para a medição da qualidade em serviço, SERVQUAL e SERVPERF respectivamente. Esse é um ponto interessante, uma vez que muitos estudos (CRONIN; TAYLOR, 1992; FINN; LAMB, 1991; JOHNSTON, 1995) contestaram a utilização da ferramenta SERVQUAL em uma ampla gama de empresas de serviços. A revisão de literatura apontou a utilização da técnica do incidente crítico (TIC) (FLANAGAN, 1954), tanto na medição da qualidade em serviço (JOHNSTON, 1995) quanto em estudos de recuperação de serviço (GOLDSTEIN et al., 2002), no entanto esses autores não aparecem na rede.

As ferramentas clássicas da qualidade utilizadas como bases para a qualidade em serviço estão 
representadas nessa análise pelos trabalhos de Dow, Samson e Ford (1999) sobre práticas de qualidade versus desempenho da qualidade; Saraph, Benson e Schroeder (1989) e Black e Porter (1996) em seus trabalhos sobre fatores críticos de gerenciamento da qualidade; a referência ao livro de Crosby (1979) sobre custos da qualidade; Powell (1995) e Flynn, Schroeder e Sakakibara (1995) em seus trabalhos sobre o potencial competitivo do TQM; Ahire, Golhar e Waller (1996) sobre o impacto das estratégias prescritas de gerenciamento da qualidade na qualidade de empresas de produtos; Flynn, Schroeder e Sakakibara (1994) em sua proposição de um modelo de investigação da gestão da qualidade e os instrumentos de medição associados; e por fim Deming (1986), uma grande referência da área de gestão da qualidade.

A utilização de conceitos clássicos da qualidade também pode ser verificada na análise das palavras-chave mais citadas (Figura 6), considerando-se que os termos mais citados foram TQM (40 citações), quality management (15 citações), management (10 citações) e performance (18 citações).

Como discutido anteriormente, a qualidade em serviço trata da impressão geral do cliente sobre a relativa superioridade/inferioridade de uma organização e seus serviços (BITNER; HUBBERT, 1995), concentrando-se especificamente nas dimensões do serviço que dependem da percepção

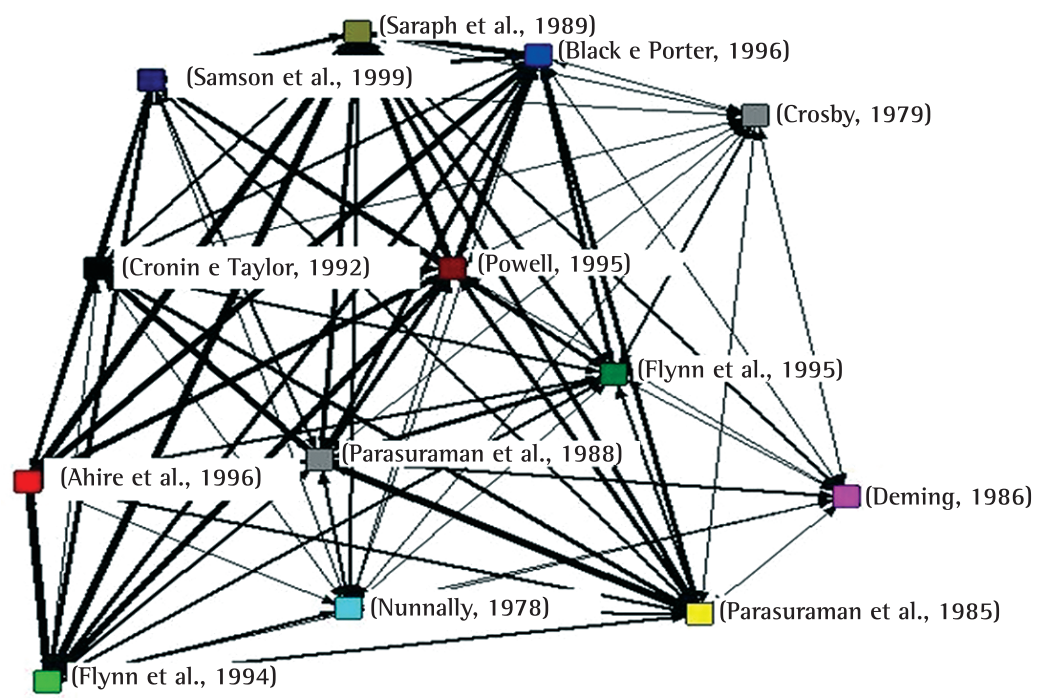

Figura 5. Análise de citação/cocitação para os trabalhos mais influentes.

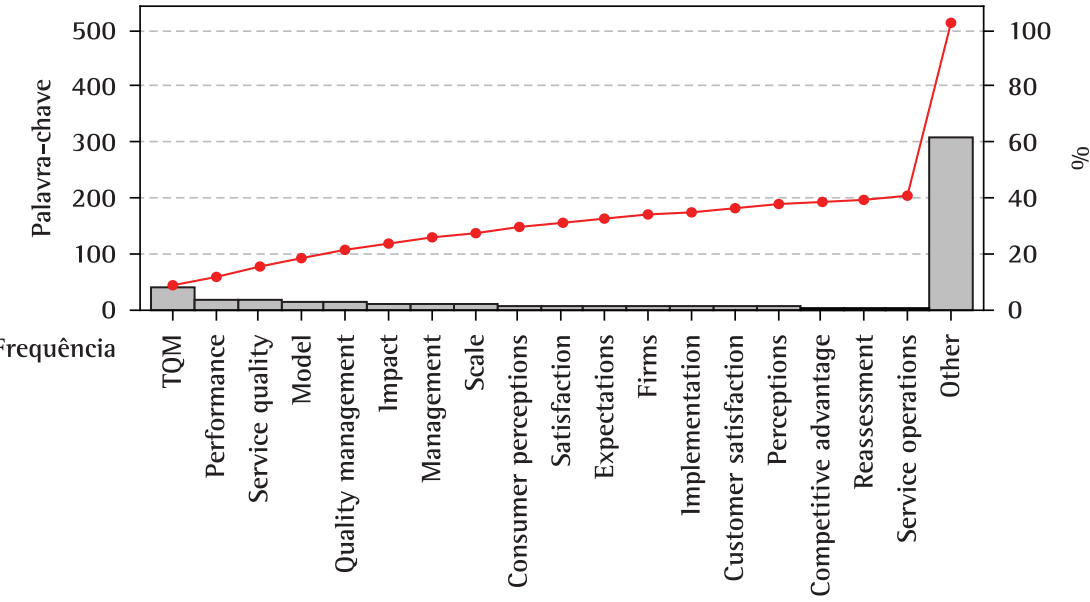

$\begin{array}{rrrrrrrrrrrrrrrrrrrr}\text { Palavra-chave } & 40 & 18 & 18 & 15 & 15 & 10 & 10 & 10 & 9 & 8 & 7 & 7 & 7 & 6 & 6 & 5 & 5 & 5 & 312 \\ \text { Percent } & 8 & 4 & 4 & 3 & 3 & 2 & 2 & 2 & 2 & 2 & 1 & 1 & 1 & 1 & 1 & 1 & 1 & 1 & 61 \\ \text { Cum } \% & 8 & 11 & 15 & 18 & 21 & 23 & 25 & 27 & 28 & 30 & 31 & 33 & 34 & 35 & 36 & 37 & 38 & 39 & 100\end{array}$

Figura 6. Gráfico de Pareto por palavra-chave. 
do cliente. Segundo Johnston (1995), é fundamental identificar os fatores determinantes da qualidade em serviço e assim poder medir, controlar e melhorar a qualidade dos serviços percebida pelo cliente, durante o processo de serviço. Seguindo essa ideia, percebe-se pelas palavras service quality, model, consumer perceptions, satisfaction, expectations, costumer satisfaction, perceptions um esforço dos pesquisadores na identificação dos componentes da qualidade em serviço e sua relação com o cliente.

Dentro do setor de serviços das subáreas de interesse que aparecem na análise de citações cruzadas (Figura 7), destacam-se educação, setor financeiro e setor público. As conexões indicadas pelas setas seguem o sentido do artigo de origem para o artigo citado e foram geradas através do software UCINET (BORGATTI; EVERETT; FREEMAN, 1999).

Um levantamento direto na base de dados identificou outras áreas de destaque dentro do setor de serviços, apresentadas de acordo com sua frequência - setor de saúde (health care), educação, serviços financeiros, banco, serviços públicos, compras, $\mathrm{Tl}$, turismo, marinha, comércio eletrônico, hotelaria, $\mathrm{RH}$, restaurante e serviço a cliente, com certa dominância nos setores de saúde (health care) e financeiro.

Por fim, a rede resultante do cálculo da similaridade de artigos baseada em suas referências comuns (Figura 8) permite uma análise dos trabalhos publicados na última década sobre o tema de qualidade em serviço. $\mathrm{Na}$ rede destaca-se um grupo central, formado pelos trabalhos com mais conexões e espessuras largas que indicam maior número de pares de artigos em comum. Esse grupo central é composto por Ang,
Davies e Finlay (2001), Zhao et al. (2004), Bennett, Lehman e Forst (1999), Brah, Wong e Rao (2000), Sanchez-Rodriguez e Martinez-Lorente (2004), Sureshchandar, Rajendran e Anantharaman (2001, 2002) e Bou e Beltran (2005).

Conforme descrição da rede de similaridade (Quadro 3) nota-se que esses trabalhos apresentam objetivos de estudo em comum que fizeram com que seus autores usassem, como base, pares de artigos iguais. Esses trabalhos tratam em geral da aplicação do TQM e do QMS (quality management system) em pesquisas empíricas no setor de serviços. Zhao, Yeung e lee (2004) e Sureshchandar (2001) abordam diretamente os modelos de qualidade em serviço (QMS). Os artigos de Sanchez-Rodriguez e Martinez-Lorente (2004) e Brah, Wong e Rao (2000) avaliam o desempenho do negócio nas áreas de compras e no setor de serviços. Sureshchandar, Rajendran e Anantharaman (2002) e Sanchez-Rodriguez e Martinez-Lorente (2004) tratam das percepções internas da organização quanto às necessidades do cliente. Ang, Davies e Finlay (2001), Brah, Wong e Rao (2000) e Bennett, Lehman e Forst (1999) focam o TQM no ambiente de serviços.

Nos trabalhos que aparecem na rede, mas que não fazem parte do grupo central, destacam-se ainda algumas semelhanças, como os trabalhos de Sharpley e Foster (2003) e Lewis e Gabrielsen (1998), que tratam da perspectiva do empregado no desenvolvimento e gerenciamento da qualidade em serviço enquanto Harrington e Akehurst (2000) aborda a dimensão humana desse processo. Hsieh, Chou e Chen (2002),

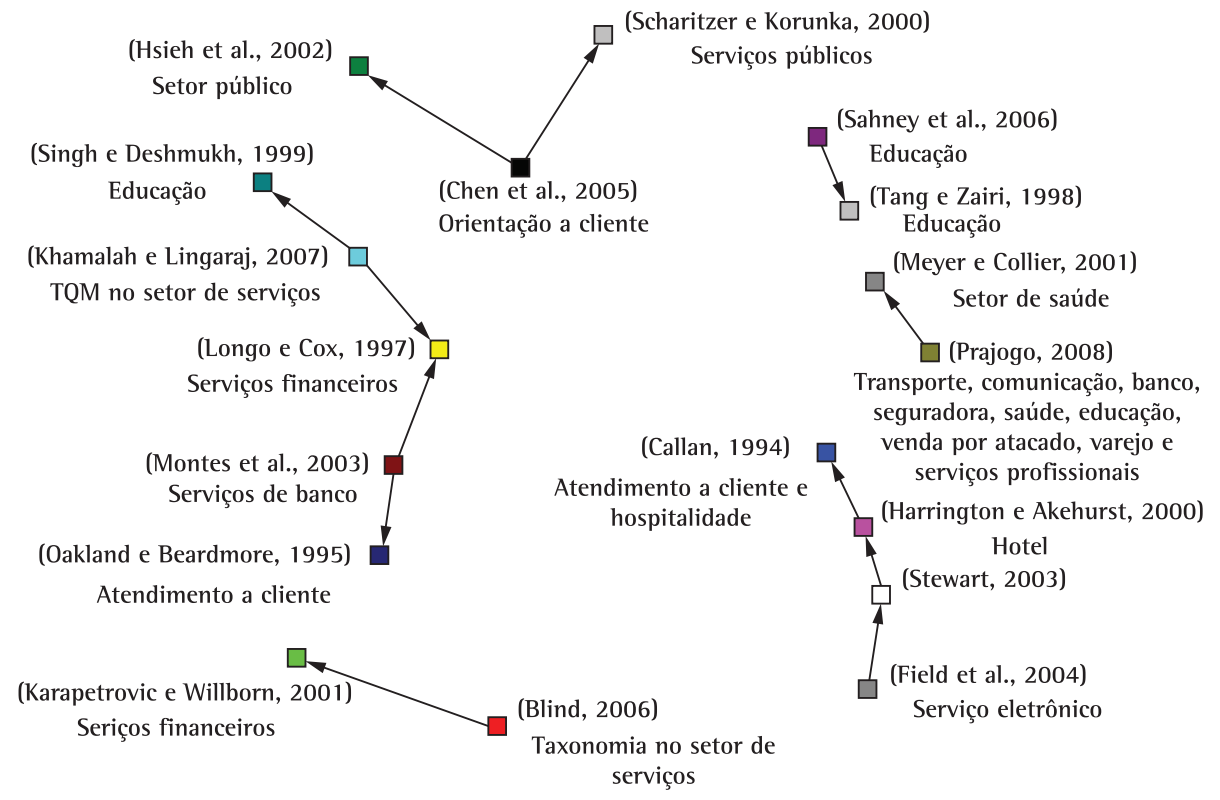

Figura 7. Análise de citação cruzada. 


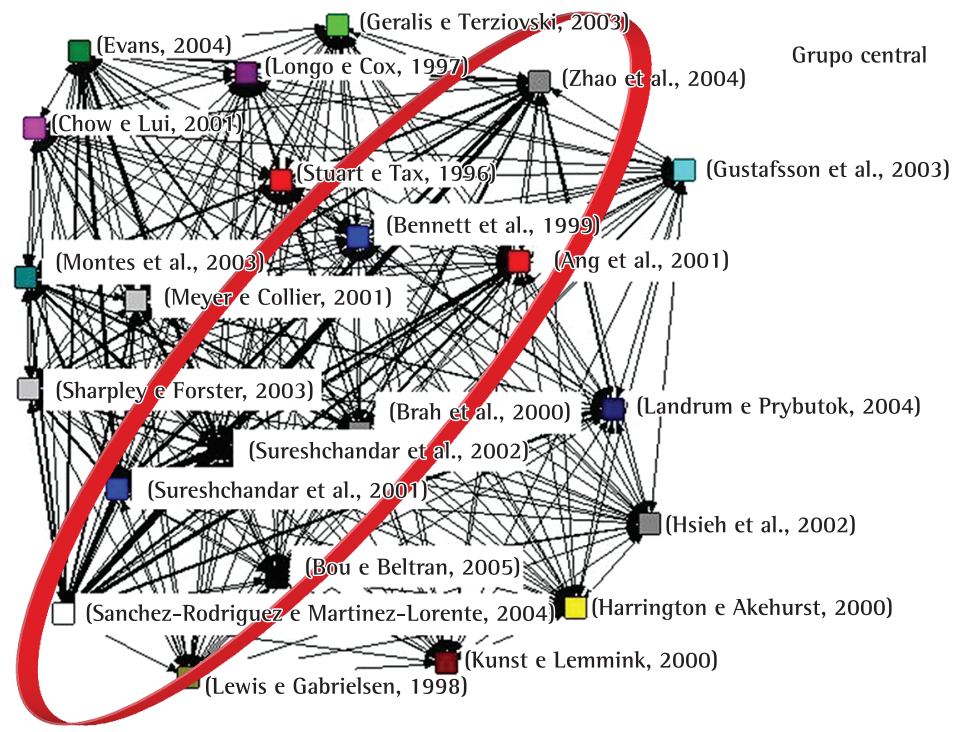

Figura 8. Rede resultante da análise de similaridade de artigos baseada em referências em comum.

Quadro 3. Detalhamento dos autores constantes na rede de similaridade.

\begin{tabular}{|c|c|c|c|c|}
\hline Autor & Ano & Assunto & Área & $\begin{array}{l}\text { Local da } \\
\text { pesquisa }\end{array}$ \\
\hline Ang et al. & 2001 & 0 uso de $\mathrm{Tl}$ no apoio ao processo de TQM & Setor público & Malásia \\
\hline Bennett et al. & 1999 & $\begin{array}{l}\text { Mudança, transferência de clima e orientação a } \\
\text { cliente - treinamento de qualidade total }\end{array}$ & Setor público & Não citado \\
\hline Bou e Beltran & 2005 & TQM e a estratégia de alto comprometimento & Empresas de serviço & Espanha \\
\hline Brah et al. & 2000 & 0 impacto do TQM no desempenho do negócio & Setor de serviços & Singapura \\
\hline $\begin{array}{l}\text { Sanchez-Rodriguez } \\
\text { e Martinez-Lorente }\end{array}$ & 2004 & $\begin{array}{l}\text { Um estudo da relação das práticas de qualidade na área } \\
\text { de compras com as medidas de desempenho operacional, } \\
\text { satisfação do cliente interno e desempenho do negócio }\end{array}$ & Compras & Espanha \\
\hline Sureshchandar et al. & 2001 & Proposição de um modelo holístico para qualidade em serviço & Setor bancário & Não citado \\
\hline Sureshchandar et al. & 2002 & $\begin{array}{l}\text { A relação entre a percepção da gerência sobre a qualidade } \\
\text { total em serviço e as percepções do cliente sobre a qualidade } \\
\text { do serviço }\end{array}$ & Não citado & Não citado \\
\hline Zhao et al. & 2004 & $\begin{array}{l}\text { Taxonomia de sistema de qualidade total na } \\
\text { área de serviços }\end{array}$ & Indústria de serviços & China \\
\hline Chow e Lui & 2001 & $\begin{array}{l}\text { Avaliação do nível de adoção do conceito de TQM nos serviços } \\
\text { de IS do governo }\end{array}$ & Não citado & Hong Kong \\
\hline Evans & 2004 & Sistema de medida de desempenho & Educação e setor de saúde & Não citado \\
\hline Geralis e Terziovski & 2003 & Empowerment $\mathrm{x}$ qualidade em serviço & Bancos & Austrália \\
\hline Gustafsson et al. & 2003 & 0 papel das práticas de qualidade em organizações de serviço & Organizações de serviço & Não citado \\
\hline $\begin{array}{l}\text { Harrington e } \\
\text { Akehurst }\end{array}$ & 2000 & Implementação da qualidade em serviço (dimensão humana) & Hotel & Não citado \\
\hline Hsieh et al. & 2002 & Relacionamento entre TQM e a qualidade em serviço & Setor público & Taiwan \\
\hline Kunst e Lemmink & 2000 & A relação entre TQM e a qualidade percebida do serviço & Hospitais & $\begin{array}{l}\text { Espanha, } \\
\text { Inglaterra e } \\
\text { Holanda }\end{array}$ \\
\hline Landrum e Prybutok & 2004 & $\begin{array}{l}\text { Proposição e teste de um modelo para verificar se a qualidade } \\
\text { em serviço é um importante fator de sucesso }\end{array}$ & $\begin{array}{c}\text { Bibliotecas - sistema } \\
\text { bibliotecário - US Army } \\
\text { Corps of Engineers Library }\end{array}$ & $\begin{array}{l}\text { Estados } \\
\text { Unidos }\end{array}$ \\
\hline Lewis e Gabrielsen & 1998 & $\begin{array}{l}\text { Aspectos intraorganizacionais do gerenciamento da qualidade } \\
\text { em serviço sob a perspectiva do empregado }\end{array}$ & Serviços financeiros & Noruega \\
\hline Longo e Cox & 1997 & TQM no setor financeiro & Serviços financeiros & Não citado \\
\hline Meyer e Collier & 2001 & Malcom Baldrige National Quality Award (MBNQA) & Hospitais & $\begin{array}{l}\text { Estados } \\
\text { Unidos }\end{array}$ \\
\hline Montes et al. & 2003 & Gerenciamento da qualidade em serviços bancários & Setor bancário & Espanha \\
\hline Sharpley e Forster & 2003 & $\begin{array}{l}\text { A influência das atitudes dos empregados de hotel no } \\
\text { desenvolvimento da qualidade do turismo }\end{array}$ & Turismo & Chipre \\
\hline Stuart e Tax & 1996 & $\begin{array}{l}\text { Como o QFD pode ser modificado e adaptado para ser usado } \\
\text { no ambiente de serviço }\end{array}$ & $\begin{array}{l}\text { Hotel (atividades do } \\
\quad \text { front-desk) }\end{array}$ & Não citado \\
\hline
\end{tabular}


Kunst e Lemmink (2000), Longo e Cox (1997) estudam a relação do TQM com a qualidade em serviço.

Os trabalhos presentes na rede são relativamente recentes, em relação ao período de publicação, variando de 1996 a 2005, com destaque para os anos de 2003 e 2004. Quanto às áreas de interesse, dos 22 artigos presentes na rede, apenas cinco referem-se ao setor de serviços em geral, enquanto os demais tratam de áreas específicas, como o setor bancário, hotéis, turismo, setor público e educação.

\subsection{Dados obtidos na base Scielo}

Com a finalidade de avaliar a produção nacional sobre o tema, realizou-se a mesma busca na base de dados Scielo. Os parâmetros da pesquisa selecionados foram "artigos", "indice de assuntos", termo de busca "servi*". 0 asterisco permite pegar todas as grafias de serviço possíveis para o inglês e português, a base inclusive não trabalha com a cedilha, que aparece no português serviço, por exemplo.

Tabela 1. Resultados da busca no Scielo.

\begin{tabular}{cccccc}
\hline Scielo & Termos & Artigos & \multicolumn{4}{c}{$\begin{array}{c}\text { Termos alinhados à } \\
\text { pesquisa }\end{array}$} & $\begin{array}{c}\text { Após } \\
\text { leitura }\end{array}$ \\
\cline { 4 - 6 } & & & $\begin{array}{c}\text { Termos } \\
\text { filtro }\end{array}$ & Artigos & Artigos \\
\hline $\begin{array}{c}\text { Produção } \\
\text { G\&P }\end{array}$ & 20 & 22 & 7 & 9 & 7 \\
$\begin{array}{c}\text { Pesquisa } \\
\text { Operacional } \\
\text { Todos os }\end{array}$ & 5 & 50 & 7 & 10 & 6 \\
periódicos & 96 & 1044 & 11 & 57 & 37 \\
\hline
\end{tabular}

A primeira busca resultou em 96 termos que continham a palavra serviço (em quatro idiomas, inglês, português, espanhol e francês), totalizando 1.044 artigos. Depois se passou a triar os termos relacionados aos serviços com tópicos de qualidade, resultando a seguinte variedade de termos na revista Produção, por exemplo: service process improvement or service quality or service recovery or services quality or servperf or servqual or servqual scale. A Tabela 1 apresenta a síntese da busca, tanto no geral como após os filtros, destacando-se as três revistas nacionais pertencentes a essa base, com maior classificação no Qualis das Engenharias 111: Produção, Gestão \& Produção e Pesquisa Operacional.

0 Quadro 4 apresenta a lista de 13 artigos da Produção e da Gestão e Produção, considerados dentro do escopo da pesquisa, já que os 5 artigos da revista Pesquisa Operacional não se encaixavam na temática.

Uma nova busca utilizando o termo em inglês service quality apresentou um resultado mais significativo, com 37 documentos selecionados. Mediante a análise dos artigos, identificaram-se as seguintes subáreas de interesse dentro do setor de serviço: saúde com 13 trabalhos, comércio eletrônico, tecnologia da informação, varejo e educação com 2 cada, fast food, financeiro, hotelaria, terceiro setor, turismo e logística com 1 artigo cada. Dois artigos sobre revisão de literatura e 5 relacionados a outras áreas.

Para que se pudesse ter uma visão da disciplina em relação ao total de produções comparada ao tema mais abrangente "gerenciamento da qualidade", optou-se por realizar uma pesquisa considerando apenas a frase quality management e assim verificar o

Quadro 4. Artigos obtidos no Scielo: revistas Produção e Gestão \& Produção.

\begin{tabular}{|c|c|c|}
\hline Autor & Ano & Título \\
\hline Battaglia, D.; Borchardt, M. & 2010 & $\begin{array}{l}\text { Análise do processo de recuperação de serviços a partir das reclamações dos clientes: } \\
\text { estudo de caso em três organizações }\end{array}$ \\
\hline Tontini, G.; Zanchett, R. & 2010 & Atributos de satisfação e lealdade em serviços logísticos \\
\hline Heckert, C. R.; Silva, M. T. & 2008 & Qualidade de serviços nas organizações do terceiro setor \\
\hline Tontini, G.; Sant'Ana, A. J. & 2008 & Interação de atributos atrativos e obrigatórios de um serviço na satisfação do cliente \\
\hline Souza, A. M.; Griebeler, D.; Godoy, L. P. & 2007 & $\begin{array}{l}\text { Qualidade na prestação de serviços fisioterápicos: estudo de caso sobre expectativas e } \\
\text { percepções de clientes }\end{array}$ \\
\hline Tontini, G.; Sant'Ana, A. J. & 2007 & $\begin{array}{l}\text { ldentificação de atributos críticos de satisfação em um serviço através da análise } \\
\text { competitiva do gap de melhoria }\end{array}$ \\
\hline $\begin{array}{l}\text { Silva, E. M. da; Yue, G. K.; Rotondaro, R. G.; } \\
\text { Laurindo, F. J. B. }\end{array}$ & 2006 & Gestão da qualidade em serviços de Tl: em busca de competitividade \\
\hline $\begin{array}{l}\text { Machado, M. D.; Queiroz, T. R.; Martins, } \\
\text { M. F. }\end{array}$ & 2006 & Mensuração da qualidade de serviço em empresas de fast food \\
\hline $\begin{array}{l}\text { Salomi, Gilberto Gabriel Eid } \\
\text { Miguel, P. A. C.; Abackerli, A. J. }\end{array}$ & 2005 & $\begin{array}{l}\text { SERVQUAL x SERVPERF: comparação entre instrumentos para avaliação da qualidade } \\
\text { de serviços internos }\end{array}$ \\
\hline Miguel, P. A. C.; Salomi, G. E. & 2004 & Uma revisão dos modelos para medição da qualidade em serviços. \\
\hline $\begin{array}{l}\text { Borenstein, D.; Becker, J. L.; Prado, } \\
\text { V. J. do }\end{array}$ & 2003 & Avaliando a eficiência das lojas da ECT do Rio Grande do Sul \\
\hline Machado Junior, J. A.; Rotondaro, R.G. & 2003 & $\begin{array}{l}\text { Mensuração da qualidade de serviços: um estudo de caso na indústria de serviços } \\
\text { bancários }\end{array}$ \\
\hline Santos, L. C.; Varvakis, G. & 2002 & SERVPRO: uma técnica para a gestão de operações de serviços \\
\hline
\end{tabular}




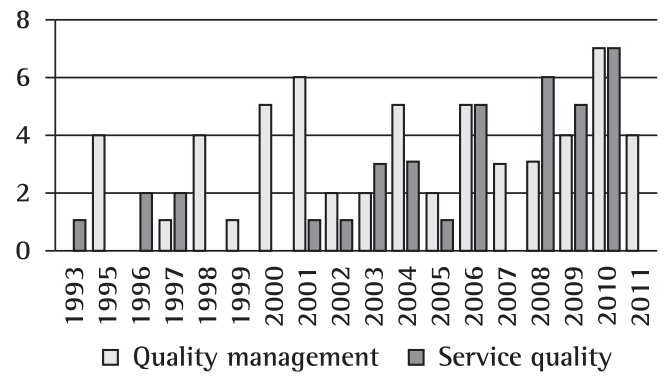

Figura 9. Número de publicações por ano na área de quality management versus service quality (Brasil).

panorama de publicação sobre qualidade em serviço. Foram identificados 58 artigos, como resultado. A Figura 9 apresenta um comparativo entre o volume de publicações por ano sobre o tema quality management e service quality no Brasil.

Com relação às ferramentas de pesquisa utilizadas, o SERVQUAL (PARASURAMAN, ZEITHAML; BERRY, 1988) destacou-se, sendo citado em $48 \%$ dos 37 trabalhos selecionados. Já o modelo conceitual de qualidade em serviço proposto por Parasuraman, Zeithaml e Berry (1985) foi citado em 43\% dos artigos.

\section{Conclusões}

As conclusões obtidas neste trabalho serão apresentadas conforme a base de dados e o método de análise utilizado, ISI Web of Knowledge, por meio da bibliometria e Scielo pela análise qualitativa dos dados.

Para análise bibliométrica dos dados provenientes do ISI Web of Knowledge, considerou-se a premissa de que autores citam documentos por eles considerados importantes no desenvolvimento de seus trabalhos (CULNAN, 1987; TAHAl; MEYER, 1999), assim, essa pesquisa identificou pontos importantes sobre a disciplina de qualidade em serviço.

Verificou-se o uso de ferramentas clássicas da qualidade como base para a qualidade em serviço. Essa tendência aparece no ranking dos artigos mais citados, na rede de citação e cocitação com destaque para autores como Deming e Juram e na análise das palavras-chave considerando-se o termo TQM citado 40 vezes.

Quanto aos autores e ferramentas de qualidade em serviço, detacaram-se Parasuraman, Zeithaml e Berry com a ferramenta SERVQUAL e Cronin e Taylor com o SERVPERF. Esse é um ponto interessante, uma vez que muitos estudos (CRONIN; TAYLOR, 1992; FINN; LAMB, 1991; JOHNSTON, 1995) contestaram a utilização da ferramenta SERVQUAL em uma ampla gama de empresas de serviços. A revisão de literatura apontou ainda a utilização de outras ferramentas como a técnica do incidente crítico (TIC) (FLANAGAN, 1954), tanto na medição da qualidade em serviço (JOHNSTON, 1995) quanto em estudos de recuperação de serviço (GOLDSTEIN et al., 2002), e que, no entanto, não aparecem nas análises.

Como discutido na revisão de literatura, a qualidade em serviço trata da impressão geral do cliente sobre a relativa superioridade/inferioridade de uma organização e seus serviços (BITNER; HUBBERT, 1995) concentrando-se especificamente nas dimensões do serviço que dependem da percepção do cliente. Segundo Johnston (1995), é fundamental identificar os fatores determinantes da qualidade em serviço e assim poder medir, controlar e melhorar a qualidade dos serviços percebida pelo cliente, durante o processo de serviço. Seguindo essa ideia, percebe-se pelas palavras service quality, model, consumer perceptions, satisfaction, expectations, costumer satisfaction, perceptions, um esforço dos pesquisadores na identificação dos componentes da qualidade em serviço e sua relação com o cliente.

Outro ponto de destaque indica a divisão das áreas de atuação dos autores de referência em dois grupos distintos, marketing e qualidade em serviço e, o segundo, gerenciamento da qualidade e gestão da qualidade total (total quality management - TQM).

Com relação ao volume de publicações, verificou-se maior destaque para os anos de 2001, 2003 e mais recentemente 2010, apresentando-se, em geral, de forma regular. No que se refere ao número total de publicações, no entanto, nota-se que o tema em questão não apresenta grandes valores ( 24 artigos em 2010) se comparado com outras linhas de pesquisa como a área de medida de desempenho, que obteve mais de 100 publicações em 2003 (NEELY, 2005).

A análise dos trabalhos mais recentes baseada na rede de similaridade de artigos destacou um grupo central em termos de interesse comum. Esse grupo é composto por Ang, Davies e Finlay (2001), Zhao et al. (2004), Bennett, Lehman e Forst (1999), Brah, Wong e Rao (2000), Sanchez-Rodriguez e Martinez-Loren (2004), Sureshchandar, Rajendran e Anantharaman (2001 e 2002) e Bou e Beltran (2005). Esses trabalhos tratam em geral da aplicação do TQM e do QMS (quality mangement system) em pesquisas empíricas no setor de serviços.

Para os dados provenientes da base Scielo, o número de trabalhos obtidos com parâmetros similares aos da pesquisa utilizados na base $I S I$ Web of Knowledge mostrou-se inferior. Observou-se o destaque das revistas Produção e Gestão \& Produção, mas também notou-se que os periódicos da área de saúde (health care), provenientes da base Scielo, são o grande destaque em termos de número de artigos sobre o tema. 0 que corrobora os achados internacionais, 
pesquisados na base ISI Web of Knowledge, em que essa área aparece entre as subáreas de maior interesse dentro do tema de qualidade no setor de serviço.

Estudos como este fornecem uma análise quantitativa do estado da arte, como um complemento, mas nunca um substituto para os métodos qualitativos tradicionais de revisão da literatura, por isso sugere-se que o trabalho seja ampliado para outras bases. Além disso, a abordagem metodológica focou nas principais bases de dados, em consequência, pode ter deixado artigos relevantes ou outros tipos de publicações de fora, tais como teses e dissertações, anais de congressos ou mesmo artigos que, pela abordagem adotada, não sejam facilmente aceitos nessas tradicionais bases de dados.

\section{Limitações do estudo}

Este trabalho adotou como critério para a elaboração da amostra analisada no estudo bibliométrico as publicações que possuíssem a frase quality management e a palavra service mencionadas no item assunto. Por isso, é possível que alguns artigos aderentes ao tema possam eventualmente não ter sido selecionados.

\section{Referências}

AHIRE, S. L.; GOLHAR, D. Y.; WALLER, M. A. Development and validation of tqm implementation constructs. Decision Sciences, v. 27, n. 1, p. 23-56, 1996. http:// dx.doi.org/10.1111/j.1540-5915.1996.tb00842.x

ANDREASSEN, T. W.; STREUKENS, S. Service innovation and electronic word-of-mouth: is it worth listening to? Managing Service Quality, v. 19, n. 3, p. 249-265, 2009.

ANG, C. L.; DAVIES, M.; FINLAY, P. N. An empirical study of the use of information technology to support total quality management. Total Quality Management, v. 12, n. 2, p. 145-157, 2001. http://dx.doi. org/10.1080/09544120120011370

ARAUJO, L. M.; SPRING, M. Services, products and the institutional structure of production. Industrial Marketing Management, v. 35, n. 7, p. 797-805, 2006. http://dx.doi.org/10.1016/j.indmarman.2006.05.013

BAINES, T. S. et al. State-of-the-art in product-service systems. Proceedings of the Institution of Mechanical Engineers Part B - Journal of Engineering Manufacture, v. 221, n. 10 , p. 1543-1552, 2007.

BATTAGLIA, D.; BORCHARDT, M. Análise do processo de recuperação de serviços a partir das reclamações dos clientes: estudo de caso em três organizações. Revista Produção, v. 20, n. 3, p. 455-470, 2010.

BENNETT, J. B.; LEHMAN, W. E. K.; FORST, J. K. Change, transfers climate, and customer orientation - A contextual model and analysis of change-driven training. Group \& Organization Management, v. 24, n. 2, p. 188-216, 1999. http://dx.doi.org/10.1177/1059601199242004

BERRY, L. L.; ZEITHAML, V. A.; PARASURAMAN, A. Quality Counts in Services, Too. Business
Horizons, v. 28, n. 3, p. 44-52, 1985. http://dx.doi. org/10.1016/0007-6813(85)90008-4

BITNER, M. J. Evaluating service encounters - the effects of physical surroundings and employee responses. Journal of Marketing, v. 54, n. 2, p. 69-82, 1990. http://dx.doi. org/10.2307/1251871

BITNER, M. J. Servicescapes - the impact of physical surroundings on customers and employees. Journal of Marketing, v. 56, n. 2, p. 57-71, 1992. http://dx.doi. org/10.2307/1252042

BITNER, M. J.; HUBBERT, A. R. Encounter satisfaction versus overall satisfaction versus service quality: the consumer's voice. International Journal of Service Industry Management, v. 6, n. 5, p. 53-71, 1995.

BLACK, S. A.; PORTER, L. J. Identification of the critical factors of TQM. Decision Sciences, v. 27, n. 1, p. 1-21, 1996. http://dx.doi.org/10.1111/j.1540-5915.1996.tb00841.x

BLIND, K. A taxonomy of standards in the service sector: Theoretical discussion and empirical test. Service Industries Journal, v. 26, n. 4, p. 397-420, 2006. http:// dx.doi.org/10.1080/02642060600621597

BOLTON, R. N.; DREW, J. H. A longitudinal analysis of the impact of service changes on customer attitudes. Journal of Marketing, v. 55, n. 1, p. 1-9, 1991. http://dx.doi. org/10.2307/1252199

BORENSTEIN, D.; BECKER, J. L.; PRADO, V. J. D. Avaliando a eficiência das lojas da ect do rio grande do sul. Gestão \& Produção, v. 10, p. 231-250, 2003. http://dx.doi. org/10.1590/S0104-530X2003000200008

BORGATTI, S. P.; EVERETT, M. G.; FREEMAN, L. C. UCINET 6. 0 Version 1. OO. Natick: Analytic Technologies, 1999.

BOU, J. C.; BELTRAN, 1. Total quality management, high-commitment human resource strategy and firm performance: An empirical study. Total Quality Management \& Business Excellence, v. 16, n. 1, p. 71-86, 2005

BRAH, S. A.; WONG, J. L.; RAO, B. M. TQM and business performance in the service sector: a Singapore study. International Journal of Operations \& Production Management, v. 20, n. 11-12, p. 1293-1312, 2000.

CALLAN, R. J. Quality assurance certification for hospitality marketing, sales and customer services. Service Industries Journal, v. 14, n. 4, p. 482-498, 1994. http://dx.doi. org/10.1080/02642069400000052

CARMAN, J. M. Consumer perceptions of service quality: an assessment of the servqual dimensions. Journal of Retailing, v. 66, p. 33-55, 1990.

CHEN, C. K.; YU, C. H.; CHANG, H. C. An empirical analysis of customer-oriented service activities in the Taiwanese public sector. Total Quality Management \& Business Excellence, v. 16, n. 7, p. 887-901, 2005. http://dx.doi. org/10.1080/14783360500077369

CHOW, W. S.; LUl, K. H. Discriminating factors of information systems function performance in Hong Kong firms practising TQM. International Journal of Operations \& Production Management, v. 21, n. 5-6, p. 749-771, 2001.

CLARK, G.; JOHNSTON, R.; SHULVER, M. Exploiting the service concept for service design and development. In FITZSIMMONS, J. A.; FITZSIMMONS, M. J. (Eds.). New Service Design. Thousand Oaks: Sage, 2000. p. 71-91. 
CORRÊA, H. L.; CAON, M. Gestão de serviços: lucratividade por meio de operações e de satisfação dos clientes. São Paulo: Editora Atlas, 2002.

CRONIN, J. J.; TAYLOR, S. A. Measuring Service Quality - a reexamination and extension. Journal of Marketing, v. 56, n. 3, p. 55-68, 1992. http://dx.doi.org/10.2307/1252296

CROOM, S. Introduction to research metodology in operations management. In: KARLSSON, C. (Ed.). Researching Operations Management. New York: Routledge, 2009.

CROSBY, P. B. Quality Is free - the art of making quality certain. New York: McGraw-Hill, 1979.

CULNAN, M. J. Mapping the intellectual structure of MIS, 1980-1985: a co-citation analysis. Management of Information System Quarterly, v. 11, n. 3, p. 341-353, 1987.

DEMING, W. E. Out of the Crisis. Cambridge: Massachusetts Institute of Technology - MIT Press, 1986.

DIODATO, V. Dictionary of Bibliometrics. Binghamton: Haworth Press, 1994.

DOW, D.; SAMSON, D.; FORD, S. Exploding the myth: do all quality management practices contribute to superior quality performance? Production and Operations Management, v. 8, n. 1, p. 1-27, 1999.

EDVARDSSON, B. et al. New service development and innovation in the new economy. Lund: Studentlitteratur, 2000.

EDVARDSSON, B.; OLSSON, J. Key concepts for new service development. Service Industries Journal, v. 16, n. 2, p. $140-164,1996$. http://dx.doi. org/10.1080/02642069600000019

EVANS, J. R. An exploratory study of performance measurement systems and relationships with performance results. Journal of Operations Management, v. 22, n. 3, p. 219-232, 2004. http://dx.doi.org/10.1016/ S0272-6963(04)00008-7

FIELD, J. M.; HEIM, G. R.; SINHA, K. K. Managing quality in the e-service system: Development and application of a process model. Production and Operations Management, v. 13, n. 4, p. 291-306, 2004.

FINN, D. W.; LAMB, C. W. An evaluation of the servqual scales in a retailing setting. Advances in Consumer Research, v. 18, p. 483-490, 1991.

FITZSIMMONS, J. A.; FITZSIMMONS, M. J. Administração de serviços: operações, estratégia e tecnologia da informação. 4. ed. Porto Alegre: Bookman, 2005.

FLANAGAN, J. C. The critical incident technique. Psychological Bulletin, v. 51, n. 4, p. 327-358, 1954. http://dx.doi. $\operatorname{org} / 10.1037 / \mathrm{h} 0061470$

FLYNN, B. B.; SCHROEDER, R. G.; SAKAKIBARA, S. A framework for quality management research and an associated measurement instrument. Journal of Operations Management, v. 11, p. 339-66, 1994. http:// dx.doi.org/10.1016/S0272-6963(97)90004-8

FLYNN, B. B.; SCHROEDER, R. G.; SAKAKIBARA, S. The impact of quality management practices on performance and competitive advantage. Decision Science, v. 26, n. 5, p. 659-691, 1995. http://dx.doi. org/10.1111/j.1540-5915.1995.tb01445.x

GERALIS, M.; TERZIEOVSKI, M. A quantitative analysis of the relationship between empowerment practices and service quality outcomes. Total Quality Management \& Business
Excellence, v. 14, n. 1, p. 45-62, 2003. http://dx.doi. org/10.1080/14783360309707

GOLDSTEIN, S. M. et al. The service concept: the missing link in service design research? Journal of Operations Management, v. 20, n. 2, p. 121-134, 2002.

GUSTAFSSON, A.; NILSSON, L.; JOHNSON, M. D. The role of quality practices in service organizations. International Journal of Service Industry Management, v. 14, n. 2, p. 232-244, 2003.

HARRINGTON, D.; AKEHURST, G. An empirical study of service quality implementation. Service Industries Journal, v. 20, n. 2, p. 133-156, 2000. http://dx.doi. org/10.1080/02642060000000028

HARTLINE, M. D.; MAXHAM, J. G.; McKEE, D. 0. Corridors of influence in the dissemination of customer-oriented strategy to customer contact service employees. Journal of Marketing, v. 64, n. 2, p. 35-50, 2000. http://dx.doi. org/10.1509/jmkg.64.2.35.18001

HECKERT, C. R.; SILVA, M. T. Qualidade de serviços nas organizações do terceiro setor. Revista Produção, v. 18, n. 2, p. 319-330, 2008. http://dx.doi.org/10.1590/ S0103-65132008000200009

HESKETT, J. L. Managing in the service economy. Boston: Harvard Business School Press, 1986.

HESKETT, J. L. Service Breakthrough. New York: The Free Press, 1990.

HESKETT, J. L.; SASSER, W. E.; HART, C. W. L. Serviços Revolucionários: mudando as regras do jogo competitivo na prestação de serviços. São Paulo: Pioneira, 1994.

HSIEH, A. T.; CHOU, C. H.; CHEN, C. M. Job standardization and service quality: a closer look at the application of total quality management to the public sector. Total Quality Management, v. 13, n. 7, p. 899-912, 2002.

JOHNSTON, R. The determinants of service quality - satisfiers and dissatisfiers. International Journal of Service Industry Management, v. 6, n. 5, p. 53, 1995.

JOHNSTON, R. Service operations management: return to roots. International Journal of Operations \& Production Management, v. 25, n. 12, p. 1278-1297, 2005.

JOHNSTON, R.; CLARK, G. Service Operations Management. Harlow: Prentice-Hall, 2001.

JOHNSTONE, S.; DAINTY, A.; WILKINSON, A. Integrating products and services through life: an aerospace experience. International Journal of Operations \& Production Management, v. 29, n. 5, p. 520-538, 2009.

KARAPETROVIC, S.; WILLBORN, W. ISO 9000 quality management standards and financial investment services. Service Industries Journal, v. 21, n. 2, p. 117-136, 2001. http://dx.doi.org/10.1080/714005025

KARLSSON, C. Researching Operations Management. New York: Routledge, 2009.

KHAMALAH, J. N.; LINGARAJ, B. P. TQM in the service sector: A survey of small businesses. Total Quality Management Et Business Excellence, v. 18, n. 9-10, p. 973-982, 2007.

KUNST, P.; LEMMINK, J. Quality management and business performance in hospitals: A search for success parameters. Total Quality Management, v. 11, n. 8, p. 1123-1133, 2000

LANDRUM, H.; PRYBUTOK, V. R. A service quality and success model for the information service industry. European Journal of Operational Research, v. 156, 
n. 3, p. 628-642, 2004. http://dx.doi.org/10.1016/ S0377-2217(03)00125-5

LEWIS, B. R.; GABRIELSEN, G. O. S. Intra-organisational aspects of service quality management: The employees' perspective. Service Industries Journal, v. 18, n. 2, p. 64-89, 1998.

LONGO, C. R. J.; COX, M. A. A. Total quality management in financial services: Beyond the fashion the reality has to take off. Total Quality Management, v. 8, n. 6, p. 323-333, 1997.

LOVELOCK, C. H. Services Marketing: people, technoly, strategy. 4. ed. Upper Saddle River: Prentice Hall, 2000.

LOVELOCK, C. H.; VANDERMERWE, S.; LEWIS, B. Services Marketing: a european perspective. Harlow: Prentice-Hall, 1999.

LOVELOCK, C.; GUMMESSON, E. Whither services marketing? in search of a new paradigm and fresh perspectives. Journal of Service Research, v. 7, n. 1, p. 20-41, 2004. http://dx.doi.org/10.1177/1094670504266131

LUSCH, R. F.; VARGO, S. L.; O'BRIEN, M. Competing through Service: Insights from Service-Dominant Logic. Journal of Retailing, v. 83, n. 1, p. 5-18, 2007.

MACHADO, M. D.; QUEIROZ, T. R.; MARTINS, M. F. Mensuração da qualidade de serviço em empresas de fast food. Gestão \& Produção, v. 13, p. 261-270, 2006. http://dx.doi.org/10.1590/S0104-530X2006000200008

MACHADO JUNIOR, J. A.; ROTONDARO, R. G. Mensuração da qualidade de serviços: um estudo de caso na indústria de serviços bancários. Gestão \& Produção, v. 10, p. 217-230, 2003.

MAGL10, P. et al. The service system is the basic abstraction of the service science. Information Systems and e-business Management, v. 7, n. 4, p. 395-406, 2009. http://dx.doi. org/10.1007/s10257-008-0105-1

MEYER, S. M.; COLLIER, D. A. An empirical test of the causal relationships in the Baldrige Health Care Pilot Criteria. Journal of Operations Management, v. 19, n. 4, p. 403-425, 2001. http://dx.doi.org/10.1016/ S0272-6963(01)00053-5

MIGUEL, P. A. C.; SALOMl, G. E. Uma revisão dos modelos para medição da qualidade em serviços. Revista Produção, v. 14 , n. 1, p. 12-30, 2004. http://dx.doi.org/10.1590/ S0103-65132004000100003

MONTES, F. J. L.; FUENTES, M. D. M. F.; FERNANDEZ, L. M. M. Quality management in banking services: an approach to employee and customer perceptions. Total Quality Management \& Business Excellence, v. 14, n. 3, p. 305-323, 2003.

NEELY, A. The evolution of performance measurement research: developments in the last decade and a research agenda for the next. International Journal of Operations \& Production Management, v. 25, n. 12, p. 1264-1277, 2005.

NEELY, A. The servitization of manufacturing: an analysis of global trends. In: POMS COLLEGE OF SERVICE OPERATIONS AND EUROMA CONFERENCE, 2007, London. Proceedings... London: London Business School, 2007.

NISHINO, T. et al. Internet kansei engineering system with basic kansei database and genetic algorithm. linköping: TQM and Human Factors, Center for Studies of Humans, Technology and Organization, 1999. p. 367-372.
NUNNAllY, J. C. Psychometric theory. 2nd ed. New York: McGraw-Hill, 1978.

OAKLAND, J.S.;BEARDMORE, D. Best practice customer service. Total Quality Management, v. 6, n. 2, p. 135-148, 1995. http://dx.doi.org/10.1080/09544129550035486

OLIVA, R.; KALLENBERG, R. Managing the transition from products to services. International Journal of Service Industry Management, v. 14, n. 2, p. 160-172, 2003.

PARASURAMAN, A.; ZEITHAML, V. A.; BERRY, L. L. A conceptual-model of service quality and its implications for future-research. Journal of Marketing, v. 49, n. 4, p. 41-50, 1985. http://dx.doi.org/10.2307/1251430

PARASURAMAN, A.; ZEITHAML, V. A.; BERRY, L. L. Servqual - a multiple-item scale for measuring consumer perceptions of service quality. Journal of Retailing, v. 64 n. 1, p. 12-40, 1988.

POWELL, T. C. Total quality management as competitive advantage - a review and empirical-study. Strategic Management Journal, v. 16, n. 1, p. 15-37, 1995. http:// dx.doi.org/10.1002/smj.4250160105

PRAJOGO, D. 1. The sustainability of 1SO 9001 in a legal service organization. Service Industries Journal, v. 28, n. 5, p. 603-614, 2008. http://dx.doi. org/10.1080/02642060801988118

RODRIGUEZ, A. R. R.; NAVARRO, J. R. Changes in the intellectual structure of strategic management research: a bibliometric study of strategic management journal, 1980-2000. Strategic Management Journal, v. 25, p. 981-1004, 2004.

ROTONDARO, R. G.; CARVALHO, M. M. Qualidade em serviços. In: CARVALHO, M. M.; PALADINI, E. P. (Eds.). Gestão da qualidade: teoria e casos. Rio de Janeiro: Elsevier Editora Ltda, 2006. cap. 11, p. 331-355.

SAHNEY, S.; BANWET, D. K.; KARUNES, S. An integrated framework for quality in education: Application of quality function deployment, interpretive structural modeling and path analysis. Total Quality Management ct Business Excellence, v. 17, n. 2, p. 265-285, 2006.

SALOMI, G. G. E.; MIGUEL, P. A. C.; ABACKERLI, A. J. Servqual X Servperf: comparação entre instrumentos para avaliação da qualidade de serviços internos. Gestão \& Produção, v. 12, p. 279-293, 2005.

SANCHEZ-RODRIGUEZ, C.; MARTINEZ-LORENTE, A. R. Quality management practices in the purchasing function - An empirical study. International Journal of Operations \& Production Management, v. 24, n. 7, p. 666-687, 2004.

SANTOS, L. C.; VARVAKIS, G. Servpro: uma técnica para a gestão de operações de serviços. Revista Produção, v. 12 , n. 1, p. 34-45, 2002.

SARAPH, J.V.;BENSON, P.G.;SCHROEDER, R.G. An instrument for measuring the critical factors of quality management. Decision Sciences, v. 20, n. 4, p. 810-829, 1989. http:// dx.doi.org/10.1111/j.1540-5915.1989.tb01421.x

SCHARITZER, D.; KORUNKA, C. New public management: evaluating the success of total quality management and change management interventions in public services from the employees' and customers' perspectives. Total Quality Management, v. 11, n. 7, p. S941-S953, 2000.

SCHILDT, H. A. Software for bibliometric data management and analysis. Helsinki Institute of Strategy and International Business, 2002. 
SCHNEIDER, B.; PAUL, M. C.; WHITE, S. S. linking service climate and customer perceptions of service quality: Test of a causal model. Journal of Applied Psychology, v. 83, p. 150-163, 1998.

SCHÜTTE, S. T. W. et al. Concepts, methods and tools in kansei engineering. Ergonomy Science, v. 5, n. 3, 2004. http://dx.doi.org/10.1080/1463922021000049980

SHARPLEY, R.; FORSTER, G. The implications of hotel employee attitudes for the development of quality tourism: the case of Cyprus. Tourism Management, v. 24, n. 6, p. 687-697, 2003

SILVA, E. M. D. et al. Gestão da qualidade em serviços de ti: em busca de competitividade. Revista Produção, v. 16, n. 2, p. 329-340, 2006.

SINGH, S.; DESHMUKH, S. G. Quality initiatives in the service sector: A case. Total Quality Management, v. 10, n. 1, p. 5-16, 1999.

SLÅTTEN, T. Antecedents and effects of emotional satisfaction on employee-perceived service quality. Managing Service Quality, v. 18, n. 4, p. 370-386, 2008. http://dx.doi. org/10.1108/09604520810885617

SLATTEN, T.; SVENSSON, G.; SVAERI, S. Service quality and turnover Intentions as perceived by employees: antecedents and consequences. Personnel Review, v. 40, n. 1-2, p. 205-221, 2011.

SOUZA, A. M.; GRIEBELER, D.; GODOY, L. P. Qualidade na prestação de serviços fisioterápicos: estudo de caso sobre expectativas e percepções de clientes. Revista Produção, v. 17, n. 3, p. 435-453, 2007.

STEWART, D. M. Piecing together service quality: A framework for robust service. Production and Operations Management, v. 12, n. 2, p. 246-265, 2003.

STUART, F. l.; TAX, S. S. Planning for service quality: An integrative approach. International Journal of Service Industry Management, v. 7, n. 4, p. 58, 1996.

SURESHCHANDAR, G. S.; RAJENDRAN, C.; ANANTHARAMAN, R. N. A holistic model for total quality service. International Journal of Service Industry Management, v. 12 , n. 3-4, p. 378-412, 2001.

SURESHCHANDAR, G. S.; RAJENDRAN, C.; ANANTHARAMAN, R. N. The relationship between management's perception of total quality service and customer perceptions of service quality. Total Quality Management, v. 13, n. 1, p. 69-88, 2002. http://dx.doi. org/10.1080/09544120120098573
TAHAl, A.; MEYER M. J. A revealed preference study of management journals' direct influences. Strategic Management Journal, v. 20, n. 3, p. 279-296, 1999. http://dx.doi.org/10.1002/(SICl)1097-0266(199903)20:3 $<279:: A I D-S M J 33>3.3 . C 0 ; 2-U$

TANG, K. H.; ZAIRl, M. Benchmarking quality implementation in a service context: A comparative analysis of financial services and institutions of higher education. Total Quality Management, v. 9, n. 8, p. 669-679, 1998.

TONTINI, G.; SANT’ANA, A. J. Identificação de atributos críticos de satisfação em um serviço através da análise competitiva do gap de melhoria. Gestão e Produção, v. 14, n. 1, p. 43-54, 2007. http://dx.doi.org/10.1590/ S0104-530X2007000100005

TONTINI, G.; SANT'ANA, A. J. Interação de atributos atrativos e obrigatórios de um serviço na satisfação do cliente. Revista Produção, v. 18, n. 1, p. 112-125, 2008. http:// dx.doi.org/10.1590/S0103-65132008000100009

TONTINI, G.; ZANCHETT, R. Atributos de satisfação e lealdade em serviços logísticos. Revista Gestão e Produção, v. 17, n. 4, p. 801-816, 2010. http://dx.doi.org/10.1590/ S0104-530X2010000400013

VARGO, S. L.; LUSCH, R. F. Evolving to a new dominant logic for marketing. Journal of Marketing, v. 68, n. 1, p. 1-17, 2004. http://dx.doi.org/10.1509/ jmkg.68.1.1.24036

WHITE D. H.; MCCAIN K. W. Visualizing a discipline: an author co-citation analysis of information science, 1972-1995. Journal of the American Society for Information Science, v. 49, p. 327-355, 1998.

ZEITHAML, V. A.; BITNER, M. J. Marketing de serviços: a empresa com o foco no cliente. Porto Alegre: Boookman, 2003.

ZEITHAML, V. A.; PARASURAMAN, A.; BERRY, L. L. Delivering Service Quality. New York: Free Press, 1990.

ZEITHAML, V. A.; BERRY, L. L.; PARASURAMAN, A. Communication and Control Processes in the Delivery of Service Quality. Journal of Marketing, v. 52, n. 2, p. 35-48, 1988. http://dx.doi.org/10.2307/1251263

ZHAO, X. D.; YEUNG, A. C. L.; LEE, T. S. Quality management and organizational context in selected service industries of China. Journal of Operations Management, v. 22, n. 6, p. 575-587, 2004. http://dx.doi.org/10.1016/j. jom.2004.08.003

\section{A bibliometric study on the evolution of Service Quality research} Abstract

The purpose of this paper was to identify the articles that have had the greatest impact on the service quality literature, as well as to analyze the trend over time. The methodology adopted was based on the bibliometric techniques of citation and co-citation analysis, which are applied to all articles published on the subject and available in the 1SI Web of Science database. This study identified 226 articles related to service quality published from 1983 to 2011. In order to assess the national production, a similar survey was conducted in Scielo (1993-2011), with the adoption of qualitative methodology. The results obtained in the citation and co-citation analysis indicated the use of classical quality models as basis for quality service. On the other hand, data analysis from both databases indicated a predominance of adoption, by researchers, of tools and authors from the '1980s and ' 90 s, with emphasis to the health care sector in terms of production.

Keywords

Service quality. Bibliometric techniques. Citation and co-citation analysis. Literature review. 